\title{
Exploring the Usage of a Video Application Tool: Experiences in Film Studies
}

\author{
Nazlena Mohamad ALI ${ }^{1}$, Alan F. SMEATON ${ }^{2}$ \\ ${ }^{1}$ Institute of Visual Informatics, University Kebangsaan Malaysia \\ 43600 Bangi, Selangor, Malaysia \\ ${ }^{2}$ CLARITY: Centre for Sensor Web Technologies, Dublin City University \\ Glasnevin, Dublin 9, Ireland \\ e-mail:nma@ftsm.ukm.my, alan.smeaton@dcu.ie
}

Received: May 2011

\begin{abstract}
This paper explores our experiences in deploying a video application tool in film studies, and its evaluation in terms of realistic contextual end-users who have real tasks to perform in a real environment. We demonstrate our experiences and core lesson learnt in deploying our novel movie browser application with undergraduate and graduate students completing a Film Studies course in Dublin City University over a semester. We developed a system called MOVIEBROWSER2 that has two types of browsing modes: Advanced and Basic. In general, students found that the features we provided were beneficial for their studies. Some issues or mismatches arose during the trial. A 'wish-list' was drawn up that might be useful for the future system developer. The contribution and achievements reported in this article are on the demonstration and exploration of how advances in technology can be deployed, and media can be accessed in the context of a real user community. Exploring the usage indicates a positive acceptance among students, besides lessons learned that are important for further investigation.
\end{abstract}

Keywords: usage data analysis, digital video application, film studies.

\section{Introduction}

As a result of developments in multimedia technologies, the prospect of wide and ubiquitous use of new media is promising in various domains; in particular, in education including the use of software, hardware, Internet applications and other related activities which can facilitate and improve learning. The use of video in Film Studies teaching and learning, for example, can bring overall usefulness and benefit, as video can be an important resource for students (Mohamad Ali and Smeaton, 2009). Film and media are more accessible and useful for a variety of purposes with the advances of information technology, and have played a part in the evolution of scholarly research and educational goals. Innovative educational technologies are possible to develop as a showcase with numerous potential benefits. Research towards integration of both technical multimedia research and user orientation plays a significant role in today's learning. A number of activities such as forums and workshops on how to deliver multimedia research to end user 
experience are starting to happen (i.e., QoMEX, 2009), showing a growing awareness of the importance of relating Multimedia research to the 'real world'.

Much work has been performed regarding the technical possibilities for multimedia content analysis, particularly video. These works usually process a video element with various automatic outcomes and analyses, such as shot boundary detection, image segmentation, and automatic detection of semantic concepts. (Mas and Fernandez, 2003; Smeaton, 2004; Smeaton et al., 1999). As its goal, much of the work has a focus on the evaluation and measurement of precision and recall for video search tasks, of the efficiency and accuracy of the techniques developed. User involvement, if any, will normally be involved only at the testing stage. Such evaluations are performed in pre-defined lab settings or sessions. Various applications of the new technologies can be developed as a showcase in order to carry out the evaluation. However, not much work has been carried out beyond this boundary where new technology in video analysis techniques are deployed and used by real end-users in real settings and with real tasks involved. User interactions with new software applications that incorporate these kinds of technologies are among the contributions demonstrated in this paper. Such true user interactions are almost never captured or considered. The objective of this paper is to discuss our analysis when exploring the usage of a video application tool as an advanced technology for real users in a Film Studies context.

The paper is organized as follows. In the following section, some background work in video content analysis and examples of working application is introduced. This includes some works in deployment that combine technology into practical usage. In Section 3 and 4, we elaborate on our developed system MOVIEBROWSER2 and explain the deployment trial to Film Studies student. It is followed by our findings and discussions that also cover some lessons learned, based on our deployment experiences and analysis. We end with conclusions and limitation of the work.

\section{Background Work}

A number of operational video application showcases have been developed applying the underlying techniques of video content analysis; particularly related to movies such as MovieBrowser (Lehane et al., 2007), Videana (Ewerth et al., 2005), and a project at the INRIA (Ronfard, 2004). These works are among the many works that are novel and consider the technical perspective of the analysis (i.e., measuring Precision/Recall and accuracy). From another perspective, they lack assessment from the aspect of real usage monitoring and evaluation. Not much work has been performed which goes beyond the boundary of end-user orientation, where the usage of these kinds of tools or showcases are actually monitored and assessed.

In addition to pure technology-driven evaluations, there is also work reported that combines technological efforts into a deployment stage where it is subsequently used by users like Físchlár (Lee et al., 2000), Newsblaster (McKeown et al., 2002), iTV (Bernhaupt et al., 2007) and SportsAnno (Lanagan and Smeaton, 2007). The Físchlár Digital 
Video Library System was developed at Dublin City University to support capture, indexing, browsing, searching, and summarizing of digital video, and has been deployed into four separate video content collections for a variety of users and application scenarios (Smeaton et al., 2004a). The four versions of the Físchlár system include TV programs (Smeaton et al., 2004b), TV news (Smeaton et al., 2004a), TRECVid video track participation (Browne et al., 2003), and nursing educational videos (Gurrin et al., 2004). Information provided to users in the system interface are based on finding and selecting a video program either using text or metadata. Supported interface elements included a key frame slideshow, a hierarchical key frame browser, and a timeline browser. Físchlár-News was one of the collections designed to support an archive to the main evening TV news broadcast. It incorporates a number of multimedia and recommendation techniques and was deployed within a University campus for several years, in which large scale testing and evaluation (performance and usability) has been carried out (Smeaton et al., 2004a). Methods used from video content analysis include shot boundary detection, key frame extraction, capture of closed captions, and the system allows for text searching, browsing and playback. An extended live usage study has been performed on Físchlár-News with 16 users using a highly qualitative and ethnographic diary (Lee et al., 2006). This study mainly emphasized the understanding of real use, the development of use over time, and the use of new technologies.

Newsblaster at Columbia University (McKeown et al., 2002) is an experimental system incorporating natural language processing techniques to automatically crawl news websites on a daily basis, and summarize and present them to web users. The system has been deployed since 2001 and was developed mainly to demonstrate its summarization robustness and the use of TDT (topic detection and tracking) technology. Researchers on the Newsblaster system had started conducting a large online evaluation to measure the usage and preferences. The system has also undergone a number of experiments, mainly on summarization efficiency (Precision and Recall), as reported in (McKeown et al., 2001).

An Austrian interactive TV (iTV) trial (Bernhaupt et al., 2007) deployed a novel TV application to a local cable TV provider in Salzburg, Austria, and ran for 4 months in 2004-5. In this paper, the authors tried to overcome the lack of research in the area that can provide actual usage data; the researchers carried out evaluation and generated results from a usability test and the findings on the use of the iTV services. In order to assess actual usage data, the system was deployed into more than 300 households. Apart from that, the design of the system also followed a user-centered design approach in order to collect more usable data. The researchers got low feedback from the trial due to some technical constraints. The system received some suggestions for improvement from the usability test findings; these are tackled in subsequent projects. Data collections from the server logs, questionnaires, and interviews were used to illustrate the findings. User acceptance of the new technology is considered low as this area was still immature. The developers followed a user-centered design in order to provide a usable system for the user, but then, due to time constrains, the improvements could not be carried out for the deployment test. The research proceeded with the improved version and was further re-deployed in 
their future work. When trying to improve the system they stuck to a user-centered design approach, whereby they took into account user characteristics, experiences, expectations, and preferences. The user test showed that users preferred a simple navigational design. The research outputs also noted several issues from the trial, such as technical, usability, and user acceptance issues. For instance, during the field trial, users reported some technical problems which proved to be one of the reasons for low usage. They identified from the deployment conclusion that usability should be taken seriously to ensure user acceptance.

SportsAnno is a video browsing system designed and developed to allow users to make comments and share opinions and ideas on soccer events with other registered users (Lanagan and Smeaton, 2007). SportsAnno was deployed during the soccer World Cup 2006. Users can browse soccer video, and at the same time, make comments and annotate while reading texts of newspaper reports related to the matches. Usage data on sports event segmentation was gathered during the deployment stage. A number of usage monitoring issues were pointed out from the deployment, such as low responses for some specific games comments. Among the solutions proposed are suggestions that the system should have an alert notification, which would inform or signal that there are new comments. Some other lessons learned were: to include direct linking and annotation that allow easier navigation; and locating video events within the report. By viewing comments of others, users will catch additional information, not available in the original newspaper report.

Examples given above are some of the work in deployment efforts that combine technology into practical system development. These trial efforts also indicate that there is growing awareness of the importance of user evaluation in realistic environments. This research direction will bring a new perspective into variety of research agenda in visual informatics that extends interaction and communication based on visual interfaces; thus, could support users in understanding media content.

\section{The MOVIEBROWSER2 Application}

We developed the MOVIEBROWSER2 to incorporate the use of a number of content analysis techniques, particularly those that identify movie scene boundaries and categorize them into exciting, montage, and dialogue scenes. MOVIEBROWSER2 uses several recent multimedia technologies to automatically process digital video content, but at the same time, we used a usability engineering process to relate these techniques to the real tasks of real users in their real environments. Our MOVIEBROWSER2 interface is shown in Fig. 1 (a) and (b). The designed interface incorporates some advanced features such as a timeline bar near the top of the screen (Fig. 1 (b)). The timeline bar will appear in three different colors, each representing different types of scenes. For example, the green band represents those scenes with Dialogues; the yellow band represents Exciting scenes; the pink band represents those scenes with Montage. These interactive timeline features were developed to provide assistance in breaking down conventional patterns of viewing and 


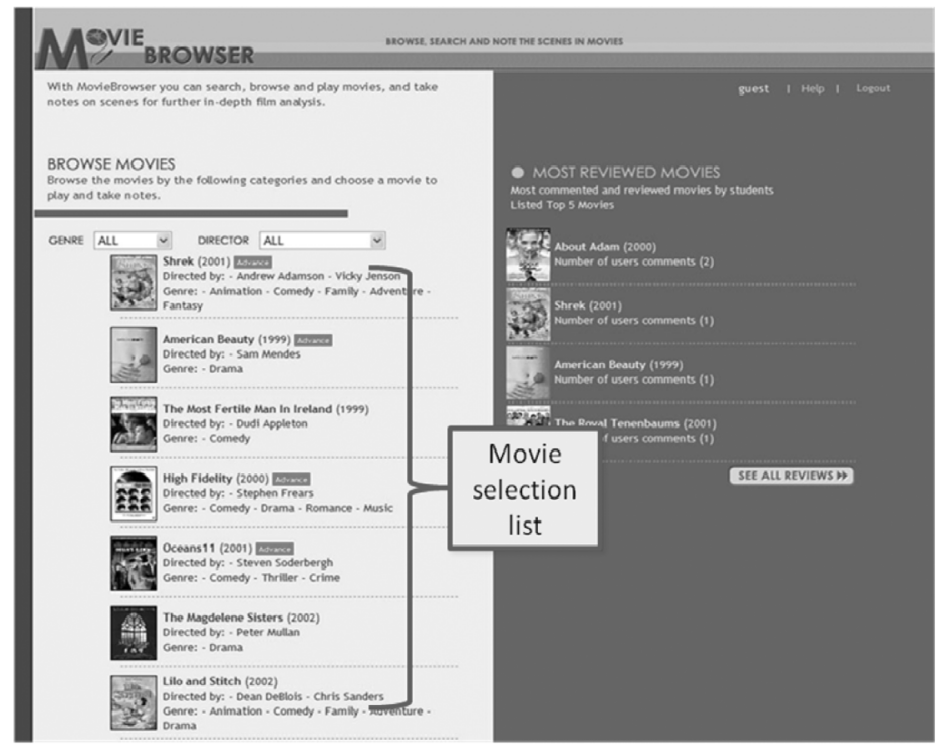

(a)

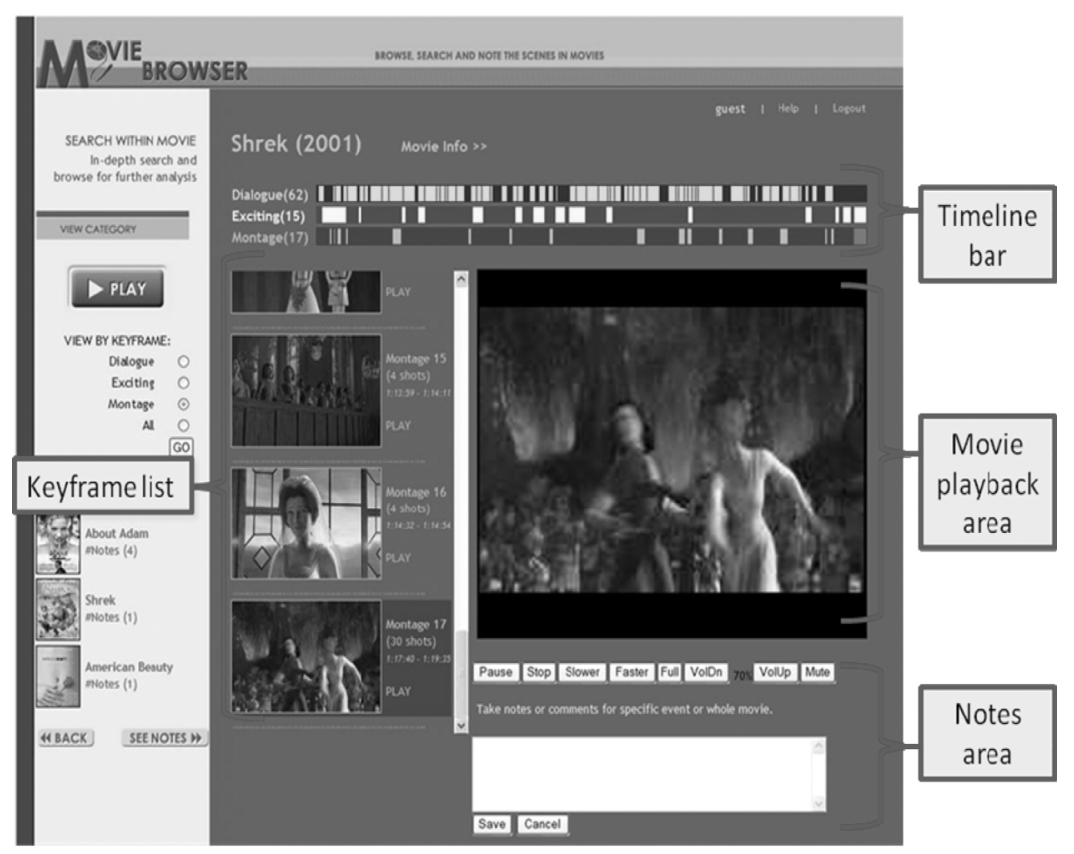

(b)

Fig. 1. MOVIEBROWSER2 screen shot (a) main page, (b) main browsing movie clips. 
helping the user to appreciate the grammar and structures of film making, and might help to break down the narrative and style of the film into its constituent parts. Enabling the film to be seen and navigated with a timeline bar outlining exactly where the sequence is, in relation to the whole film, might be useful when students are trying to understand narrative construction and the different functions of any given scene in a film. Such initial impressions are necessary to later help develop a more reflective as well as an intuitive engagement with the movie content (Brereton, P., personal communication, August 5, 2009).

MOVIEBROWSER2 provides the main features that, we believe, could support the process of reading a movie for Film Studies students. The function can be divided into four major categories:

(1) Selecting a movie - list of movie posters with some other information (i.e., titles, genre, year) on the left side of the screen as shown in Fig. 1 (a).

(2) Browsing within-movie - the user can browse using the timeline bar on the upper side of the screen and using a key frame view as shown in Fig. 1 (b). Each timeline represents a segmented scene of dialogue, exciting, or montage that is identified in each movie.

(3) Playing a movie - standard buttons as can be seen in the normal media player were provided in MOVIEBROWSER2; namely, play, pause, stop, full screen, volume adjustments and mute for the user to play movie clips. The playback area in MOVIEBROWSER2 can be seen in Fig. 1 (b) at the right side of the interface.

(4) Social interactions - we provide a feature so that, at any point during the playback, the user can make notes by clicking on the 'Make Some Notes/Comments' button underneath the playback area, and then type a note on an interesting scene or the whole movie; which, perhaps, can be saved and viewed later and even shared with other students (Fig. 1 (b)).

\section{Deployment Trial Methodology}

We deployed our MOVIEBROWSER2 system in groups of Film Studies students in School of Communications, Dublin City University. Students used the conventional approach, whereby they got DVDs from the University library or rental shop and used these as the basis for readings of movies as part of course assignments. The main restrictions contributing to the problems in their studies were, getting short-term loans, and a lack of DVD resources (i.e., old production year, obsolete format). In preparing to write a textual analysis for their course, students of Film Studies are given a list of topics to be chosen from prior to that. Once decided on the particular topic, students start looking for related DVD movies. The length of the textual analysis varies across modules from 1,000 to 3,000 words, which depends on the level of the module. There is no unique formula to decode a film. A textual analysis must engage with the grammar of the cinema and the most important thing is to concentrate on how the meaning is created (Brereton, 2008a; Brereton, 2008b). The typical tasks of Film Studies students are to read and 
analyze movie sequences. Reading a movie in their context refers to the process of understanding and analyzing movie content closely, looking for different levels of meaning and critique for example from elements like framing, depth of field, plot, shots, camera angle, lighting and so on. On a broader level it also involves an understanding of the generic conventions and narrative structure of individual movies (Brereton, 2008a). Our current design of browsing movie content could also provide a positive impact and will aid in film analysis and could provide an indirect process of reading a film. In relation to the MOVIEBROWSER2 system we developed, we believe that this new strategy and 'tool' is also useful to help students to acquire the skills of reading film and there are some elements or interface features that could maximize the potential of their learning. For example, enabling the film to be seen and navigated with a timeline bar, outlining exactly where the sequence is, in relation to the whole film, for example, might be very useful when students are trying to grapple with narrative construction and the different functions of any given scene in a film.

\subsection{Participants}

Our group of real users at the deployment stage were students from the modules CM272 National and Ireland Cinema, which is a second year undergraduate level course of one semester (12 weeks classes), and CM135 Analyzing Media Content, a first year undergraduate level module, also of one semester duration. The combined class groups totaled 268 students (CM272 $=76$ students, CM135 = 192 students). For the former module, the lecturer used mostly an Irish cinema maker as their main focus, while the latter module used contemporary Hollywood movies. Students taking the modules were from different degree programmes including the BA in communications, the BSc in multimedia and the BA in journalism. In both modules, the students' main task as part of their practical assessment is to "read" movies and analyze the film in detail based on what they have learned in class (i.e., wide range theories, historical context of cinema and etc) and from this "reading" they are required to produce an essay on a certain topic. There is no written examination at the end of either module. Student assessments are based on the essays they produce from reading the movies. For instance, in the CM135 module, students need to produce an essay on any chosen movie, of approximately 1000 words in length. This task involves an individual reading of a sequence of any chosen movie. Each student needs to analyze a movie from various aspects such as grammar of the cinema, mise-en-scene (what is in the frame), capturing the essence in the movie, focusing on aspects like music, camera, lighting, and others.

\subsection{Tasks}

As part of our end-user involvement effort, we deployed our application for managing and browsing movie contents to film study students (taking modules CM272 and CM135) for the duration of the whole spring semester. We provide two types of browsing features in our tool; Basic and Advanced interface. The advanced type of browsing (Fig. 2 (b)) has 


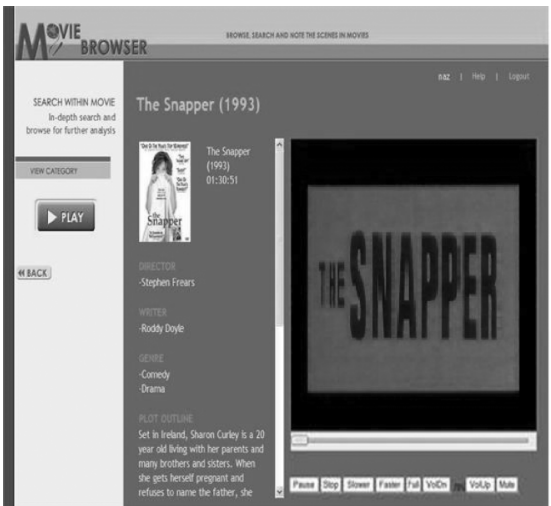

(a)

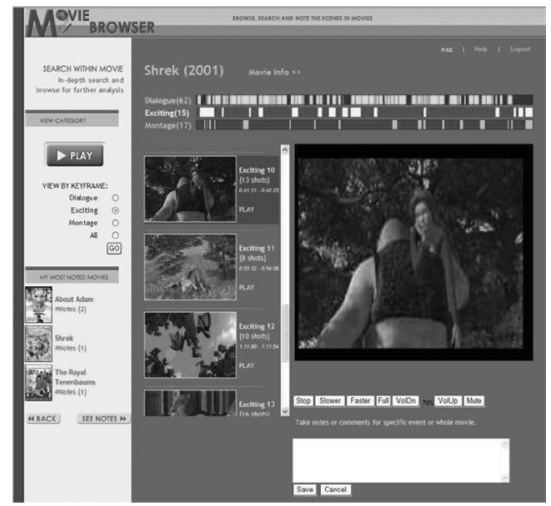

(b)

Fig. 2. Example of screenshot page (a) basic interface (b) advanced interface.

features that could enhance user browsing, like the inclusion of a visual timeline, support for key frame browsing, note taking features. On the contrary, some of the movies were listed under the basic category interface-type of browsing that provides only a basic playback function with normal standard DVD-like player interface facilities such as play, pause or slider bar (Fig. 2 (a)). The collection of 30 movies came from various genres (i.e., comedy, drama, romance, and action), ranging from contemporary Hollywood movies to old Irish movies, with production years from 1952 to 2004 as listed in Table 1.

Table 1

List of Movies in MOVIEBROWSER2.

\begin{tabular}{ll}
\hline With advanced features & With basic features \\
\hline Shrek $(2001)$ & American Beauty $(1999)$ \\
About Adam $(2000)^{* * *}$ & The Most Fertile Man In Ireland $(1999)^{*}$ \\
Circle of Friends $(1995)^{*}$ & High Fidelity (2000) \\
Intermission $(2003)^{*}$ & Oceans 11 (2001) \\
Into The West $(1992)^{*}$ & The Magdelene Sisters $(2002)^{*}$ \\
Man About Dog (2004)* & Lilo and Stitch $(2002)$ \\
Michael Collins $(1996)^{*}$ & Road To Perdition $(2002)$ \\
On The Edge $(2001)^{*}$ & This Is My Father $(1998)^{*}$ \\
Spin The Bottle $(2003)^{*}$ & The Royal Tenenbaums $(2001)$ \\
The Quiet Man $(1952)^{*}$ & Eat The Peach $(1986)^{*}$ \\
The Butcher Boy $(1991)^{*}$ & Poitin $(1979)^{* * *}$ \\
Korea $(1995)^{* * *}$ & After 68 (1993)*** \\
Nora $(2000)^{* * *}$ & Goldfish Memory $(2003)^{* * *}$ \\
- & The Shipper $(1993)^{* * *}$ \\
- & The Visit $(1992)^{* * *}$ \\
- & The Ballroom of Romance $(1982)^{* * *}$ \\
- & Bent Out of Shape $(1995)^{* * *}$ \\
\hline
\end{tabular}

Note: * Irish-directed movies; ${ }^{* *}$ movie used in CM272 module. 
There were a few movies that were short in duration (less than 1-hour) that were used in class such as After 68 [25 minutes], Bent Out Of Shape [27 minutes], The Visit [19 minutes] and The Ballroom of Romance [50 minutes]. These movies were categorized under the standard browsing features due to their short lengths and difficulties in generating event detections and classifications as a result of that short length. We tried to balance the number of movies that were categorized into 'Advanced' or 'Basic' interface. Movies with (**) are examples of Irish-directed movies that are also used as part of the discussions in the CM272 module.

\subsection{Procedures}

We provided a system demo in the earlier part of the semester for each class. The lecturers for each module were acknowledged and informed of the whole procedure before any deployment was carried out; they gave great support and encouragement for the process to proceed. A brief explanation was given to each class regarding the usage of the system, during a demo presentation of about 15 minutes, after which an email was sent to all the students, informing them of their individual system username and password, along with information on the system (i.e., web links, player installation and other requirements). Follow-up email reminders were sent a few times during the period of deployment. We administered an online questionnaire in week-13 and week-14 of this initial deployment. Students' usage data logs were captured automatically. At the end of the deployment, an email was sent to students to thank them and acknowledge their responses and cooperation.

\subsection{Data Capture}

We separated the captured data as follows:

- Usage Logs: Our objective in performing the deployment on the students in the University was to monitor and assess their actual-usage data of the developed movie browsing and playback tool. Among the logs captured were the interactions or user actions with the features that we provided on the screen interfaces, either Basic or Advanced.

- Questionnaires: The objectives of the administered online questionnaires was to measure subjective satisfaction and overall acceptance with the new deployed system, and to collect quantitative and qualitative data on the system we deployed. This included questions on the demographics on students' gender, age, course information, and other preliminary inquiries; as well as their overall reaction to the system in terms of perceived satisfaction, features provided, and opinions on the value of technology incorporated.

\section{Findings}

Our findings from our various types of logging and qualitative assessments are divided into users, and user interface features, which we now present. 


\subsection{Users}

Out of a total of 268 students in both classes, 107 students (40\%) accessed the MOVIEBROWSER2 at least 2 times during the deployment period, which tells us that they were not all wholly engaged with the system. 17 users (16\%) each accessed the system for up to 8 hours in total, most over several sessions. As shown in Table 2, the total access duration time was approximately 86 hours $(\mathrm{CM} 272=57$ hours, CM135 = 29 hours). All 7 Hollywood movies that were stored in the system library were accessed a total of 73 of times (39\%), with Shrek (2001) being mostly accessed and viewed by students (Fig. 3). At first glance this may not seem substantial, but deeper analysis shows that the access was very focused on the students' tasks, thus was a time-saving service.

Table 2

Advanced and Basic page hours spent

\begin{tabular}{ll}
\hline Type & Hours spent \\
\hline Advanced screen & 45 \\
Basic screen & 33 \\
Total playback activities (Advanced and Basic) & 78 \\
Total accessed hours in the semester & 86 \\
Other activities* & 8 \\
\hline
\end{tabular}

* Other than playback activities.

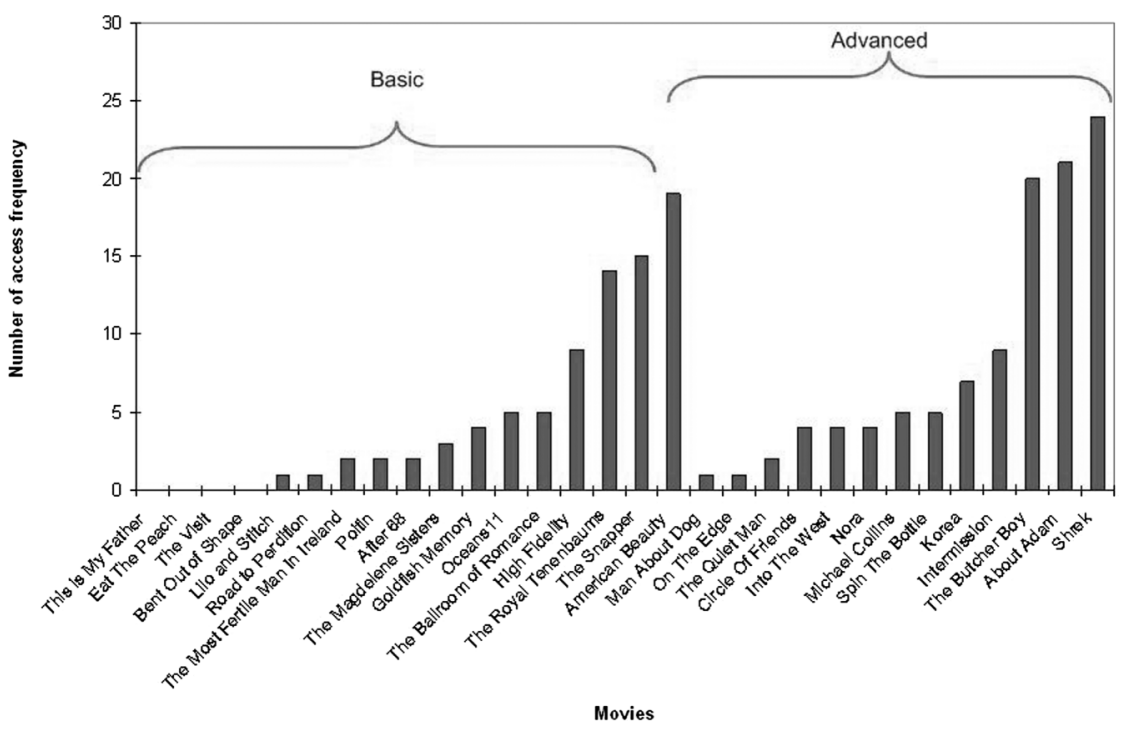

Fig. 3. Advanced vs. Basic viewed movies. 


\subsection{Interface Features}

We divided our movie collection into 'Advanced' and 'Basic' to see the pattern of user interactions when extra features were incorporated. The advanced browser has features mainly designed to enhance the movie reading based on the three event categorizations (i.e., montage, dialogue and exciting). Extra interactions were found, the extra features including a timeline visual display, note taking, and the shot key frame view. There is an indication that users are engaged more on the advanced page, and this result is also reflected by the increased hours spent on the advanced interface as can be seen from Table 2, with 45 hours spent as compared to 33 hours in the standard or basic interactions.

\subsection{Usage Over Time}

Figure 4 illustrates group usage over the full semester deployment. Students started using the system from the 10th of March. The system had quite heavy usage approaching the deadline for the assignment on May 9th for both modules. It is believed that students tend to concentrate on their assignment just before the deadline. Increased usage was found during the month of April and into the early weeks of May. These patterns strongly suggest that students were engaged with assignments from other modules and had to follow their own priority deadlines.

We also observed some usage by students after the trial deployment and assignment deadline, but that is not shown in Fig. 4, as they still had access to MOVIEBROWSER2 at this time. This pattern indicates positive acceptance of the system, but we cannot be certain of this without engaging with the students more deeply through interviews and questionnaires, which we now report on.

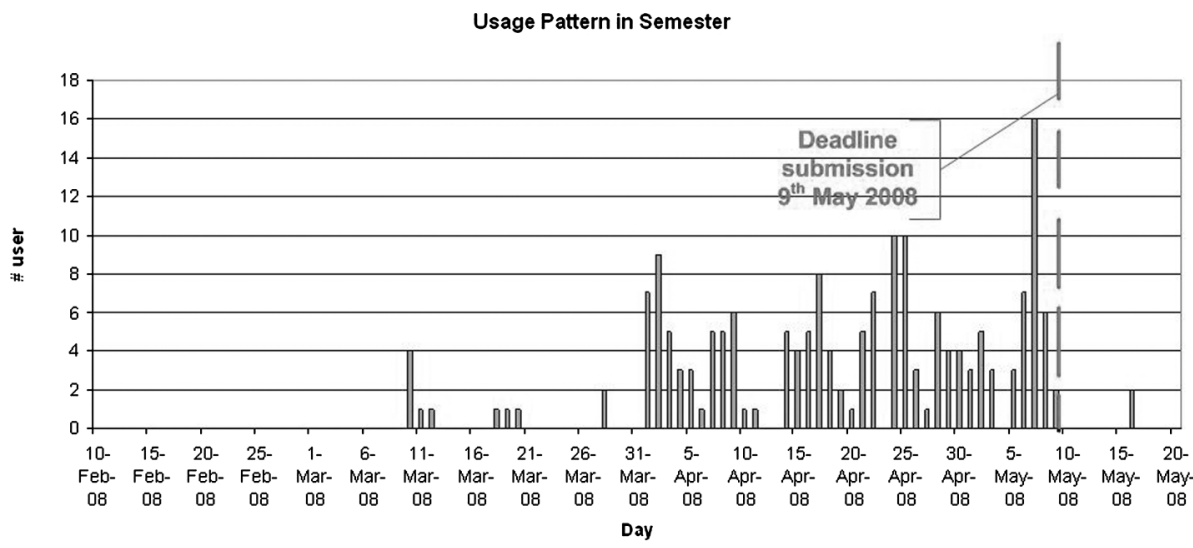

Fig. 4. Students' usage in the semester. 


\subsection{User Opinions}

60 students $(56 \%)$ responded to questionnaires that we administered during weeks 13 and 14 of the semester, using a scale from 1 to 5 ( $1=$ Totally Disagree; and $5=$ Totally Agree). At least $50 \%$ of participants gave a positive opinion on overall reactions to the system; either 'Totally Agree' or 'Agree'; while negative opinion does not exceed $10 \%$ of the total number of responses. In general, we obtained above average values with mode and median equal to 4 (Agree) for all differential statements.

In addition to quantitative evaluation, we sought more qualitative feedback from users through interviews, and overall comments given by students affirm the survey ratings. The comments include the following extracts:

- "I love it !"

- "Easy to understand and use”.

- "Yes, I seem to watch more movies with the interest of study in mind (i.e., looking at camera angles, edits etc) which I never did before having the browser".

We captured students' opinions on their learning perception as related to their studies, and how the MOVIEBROWSER2 tool might support their learning. Statement 1 in the questionnaire was, "The features provided in the tool were useful in my studies". This statement gets the highest positive response as compared to the rest of the statements (68\% of students totally agree or agree), although 13 students $(22 \%)$ gave "Neutral" responses. Statement 2, "The movie collection is useful in my studies", draws out nearly half participants to totally agree or agree (47\%), and 20\% (12 participants) gave the opposite opinion. Statement 3, "The tool helped me to support my information needs", elicited $52 \%$ of responses as total agreement. Statement 4 , "The tool helped me to enhance my ability to read films well", and statement 5, "The tool helped me to discover new ideas in my work", elicited $43 \%$ and $37 \%$ each, for totally agree or agree opinions. These statements are more abstract and related to the learning ability of individual students and their skills, which seems difficult to justify. However, we received positive comments such as, "Helped me look for styles used in film, i.e., camera cuts, shots etc.", and, "The tool helped me to choose what film to use for my assignment". The last two statements in the questionnaire, "The tool helped me to explore the collections better", and, "The tool helped me to analyze the scenes better than a DVD", draw out more than half of opinions in total agreement (53\% and 58\% each).

To identify the features or system functions that students liked or disliked, we gave students opportunities to provide qualitative feedback on each. Table 3 summarizes several items mentioned most frequently by users of the system - both likes and dislikes, based on questionnaire responses. From the table, it can be seen that note-taking was among the most frequently mentioned features (likes) as $21(30 \%)$ out of the total (71 mentioned), followed by event categorization (24\%), timeline (18\%), key frame view (11\%), and playback of the movie (8\%).

The facility to take notes while playing a movie scene seems to be an obviously advantageous function. The timeline visual and key frame view which highlight where the action, dialogue, and montage scenes overlap in a movie were praised as very useful, 
Table 3

Frequency of mentioned system features

\begin{tabular}{lll}
\hline Features & System-likes & System-dislikes \\
\hline Note-taking & 21 & 1 \\
Event categorization & 17 & - \\
Visual timeline & 13 & 1 \\
Keyframe view & 8 & 1 \\
Movie playback & 6 & - \\
\hline Other: & & \\
System design & 4 & 3 \\
Access & $2 *$ & $3 * *$ \\
Limited movies & - & 10 \\
Streaming problem & - & 9 \\
Compatibility & - & 3 \\
Total Mentioned & 71 & 31 \\
\hline convenience, ${ }^{* *}$ less coverage. &
\end{tabular}

indicating that a strong temporal orientation with additional cues on movie content is useful, as some comments below illustrate:

- "The timeline feature was probably the most useful feature on the browser".

- "The timeline as it breaks down the film into the various sections - montage, action, dialogue, etc. - this makes it easier to carry out a more in depth analysis of the movie".

- "Timeline. Much easier to navigate through a film".

The first five features in Table 3 reveal the results on interface features. We noticed some other positive features from reading participants' comments which we categorize under "system design and access". For example, in the system design, comments were mainly on the clear presentation layout which makes it easy to navigate. We also collected feedback on what matters distracted our users (did not like). There are very few comments related to system features as there was only one mention found each for the timeline, notes, and key frame view aspects. We also noticed an accessibility problem as the most-mentioned issue in the 'system-dislikes' column, namely the limited number of movies that were stored in the library which might restrict usage. Other comments we read were such as system compatibility (i.e., MAC user/Internet browsers). The trial version of MOVIEBROWSER2 was only compatible with Internet Explorer and Windows. Ease of access in the 'system-likes' column, meant, as a convenience factor by users; but in the 'system-dislikes' column, it meant, less coverage of access. When comparing the frequency of mentioned items which were either likes or dislikes, we noticed that no issues arose much on the "system design" and "features provided" aspects. Most of the system dislikes were related to the system accessibility issue.

We also asked our users about their overall experiences in using MOVIEBROWSER2 after the semester was completed. Among these 60 students, 43 of them (72\%) said they would use it in future. We calculated the positive and negative expressions of their over- 
all experiences, and we estimate that 19 of them (32\%) gave positive expressions and only 4 (7\%) gave a negative tone of expression, while the rest 37 (62\%) did not express either positive or negative expressions. Examples of positive expressions include "I'm very happy/discovered ..." and "I found it is useful/able to ...", and negative such as "Not enough/database is too small ...". "Not enough movie selections or small database" refers to only thirty movies that are available to be accessed. Some of the other user comments are repeated below:

- "Very happy with the system overall, I think 1 would like to use it more in the future as I found it useful".

- "The tool made my work much quicker. It was generally very helpful. Sort of like an upgrade. Metaphorically speaking, I am now driving, while I had just been cycling".

- "Brilliant system! Hopefully in the future it will work on MACs and on different Internet browsers!"

- "I was able to complete my assignment using some of the skills I had required on this site. The tools provided for reading a film were new to me and my work benefited greatly from these".

Finally, we sought feedback from students on their wishlists of features for future versions. Some of these appear due to the difficulties in the implementation and would not be expected during the development design stage. The list of entries was classified into the following:

- Larger and varied type of movie database (i.e., Irish, Hollywood or Europe).

- System compatibility (i.e., other browsers and MAC users).

- Improved accessibility (i.e., off-campus).

- Technical constraints (i.e., high-speed access).

\section{Discussion}

Our findings have raised several issues for discussion which we now address, including users, features, the mismatch between these, and the lessons we learned.

\subsection{Users}

The results from our deployment established the usage pattern on how the students of Film Studies used the newly-introduced application that adopted advances in multimedia technologies. Out of 268 students, 107 (40\%) used the software application for over 86 hours during the trial. Some students would have preferred to access such material from off-campus, and given the ease with which video can be streamed from services such as YouTube and Netflix, there is an expectation among users for this same level of availability from all video services. We consider how these limitations would have affected usage. This may be the reason why $60 \%$ of the students did not use the system. 


\subsection{Interface Features}

The time spent by students on the 'Advanced' page that provides extra features for an enhanced type of browsing experience was much longer than the 'Basic' page that only can play the movie using standard navigational buttons. In addition, the captured usage logs show much greater levels of interaction with the advanced system. This suggests students are more engaged with the afforded features. Positive comments on these features such as timeline, key frame browsing and event categorization, support this hypothesis. Users jumped from one point in the movie to another point easily in the movie, using visual representations of a timeline or the shot key frame view. Instead of playing sequences from the normal playback interaction, for example, either using the pause button or slider bar, the playback of sequences shifted to playing from the shot key frame view. These artificial divisions were found to influence usage among the students as provided in the Advanced system.

However, just because there are more clicks and greater system interaction does not necessarily mean that there is better usage or enhanced user experience. It might mean that it is more complicated to use or features new things, thus users need to explore more to find out what they are looking for. The findings in the qualitative comments given by students reveal a list of system-likes for these extra features as well as some complaints from students about having no advanced features for some movies. With these comments, we can deduce that the greater amount of interaction and longer time spent is not perceived as a negative during the deployment.

The design interface might influence the "play" element, in which movies were categorized into event types with a timeline and a key frame shot view. Thus it will affect the users' perceived enjoyment in using the system, where using it becomes less like work and more like play. We relate this phenomenon to the flow theory in work and organizational psychology, identified by Csikszentmihalyi $(1991,1997)$ where someone can experience flow when the technology being used actually eases the burden of their physical effort. This is one of the many ways of achieving flow which is evidenced here from users' positive expressions and overall experiences in using the software as reported earlier. Measuring flow (timelessness) or play elements in a software application that incorporates novel technology could be an interesting future research path. In this paper, we only provide the rationale for this phenomenon in interpreting our findings.

\subsection{Dealing with Mismatch}

In response to early requirements analysis, we incorporated a note-taking feature into MOVIEBROWSER2. Being able to write down comments or ideas at any point during a movie was identified as an important and useful feature from the very beginning, when initial student needs were captured. However, the feature was underused during the deployment period, as according to the log interaction data, it was only used by three students. This shows a mismatch between what our users said would be beneficial and what they actually used in practice. Interestingly, in the post-trial questionnaire, we got very positive responses regarding the benefit of this feature, even though they did not actually 
use it. Two of the three participants who actually used the notes feature commented very positively about the feature in their post-trial questionnaire (the third participant did not respond to the questionnaire).

- "Note-taking, it helps you keep track of information you are taking down on a particular part of the movie and helps you remember".

- "I liked the note-taking the best as I could take notes quickly and easily during a sequence".

- "Note taking section is very useful".

- "The way that events are organized, the ability to take notes, all movies on the course were available and they are not readily available elsewhere".

After deployment, we performed a qualitative investigation as to why they did not use this feature during deployment, and received feedback from 15 participants. The reasons for not using the notes feature during the trial were analyzed and grouped into categories summarized as following:

- Privacy issue: "I don 't want my colleagues to steal my ideas!"

- Preference for conventional practice: "I like to write with pen and paper!".

- Access limitation: II wanted to do it at home!"

\subsection{Lessons Learned}

From our experiences and analysis we formulated a number of lessons learned which include things that were not expected, and for each of these we have a number of suggestions.

- The mismatch between user requirement and actual use - we followed the usability engineering method from the very beginning of the application development that included a user requirements stage which took place before the system was built. We conducted interviews and observations, but in the system deployment stage we found that note-taking was underused. This shows a mismatch between the needs we captured and the actual practices from the user. In the system testing for the developed system, we did not foresee this situation as users always gave good feedback on the features we provided. Furthermore, they were not really attached to any usage of the software application as it was only for testing purposes before we underwent a real deployment stage which identified the mismatch. This tells us that we should be more understanding and aware of the usage context when designing such applications. Further system design should emphasize the context of usage even more, rather than simply the functions that the features can provide.

- Accessibility factors - the features that were provided in the application did not raise many issues during the trial, compared to the benefits of accessibility. The accessibility of the application was clearly an important criterion which led to high usage. An improvement in the system accessibility would increase the usage among users even more so.

- Expert point of view - from the academic point of view there is always an inherent difficulty reading a movie as it is a very subjective experience. The academic 
teaching processes attempt to make this as objective and scientific as possible, so that students can learn the skill of writing an analysis of film using robust strategies. This has been an agenda item for a long time now, in the domain of Film Studies. We discovered that developing an end-to-end system that leverages current research, and deploying this into a real usage situation (Film Studies context), is difficult, because some of the technology elements are immature and can easily hinder the usage and perceived value of the system.

\section{Conclusions}

The paper presents our findings when exploring the usage of a video browsing tool which was made available to students of Film Studies as part of their University curriculum. The results presented highlight some interesting findings for students of Film Studies in browsing and playing movie content. User access and usage were found to be varied and influenced by many factors. In general, students found the features we provided were beneficial for their studies. Some issues or mismatches arose during the trial. A 'wishlist' was drawn up that might be useful for the future system development. Our biggest strength in this study was the fact that the interactions we logged and observed were from real users, students of the School of Communications at Dublin City University. Our deployment was a longitudinal study for a real module over a whole semester, and was found to be a useful (although time-consuming) exploration process. A mismatch between students' initial wishes for a 'note/comments' feature and its actual usage during the trial triggered more questions for us, of how users' wishes collected at the requirements engineering stage should be interpreted in the context of usage, rather than treated as an isolated feature in itself.

This work provides insights into how a technologically-oriented research field, normally driven by technical perspectives of novel multimedia analysis, could be aligned to a real-world setting with real users who have real information needs. Bridging the gap between real usage with and technical possibilities was described in this paper, and the novelty factor is that we filled the gap of assessing real usage from the deployment and monitoring process into real end users and their real contextual environments. Little previous work has been reported in this area, logging and interpreting user interactions with new software applications that incorporate new kinds of technologies in a real, operational setting.

This study, however, also has its limitations. In this trial deployment, we designed and deployed a tool that has some technical constraints, thus we could not get optimum usage from our users. Future work should consider further improvement in the application itself as well as more users, and should be carried out over a longer period of time.

Acknowledgments. The work was supported by the Ministry of Higher Education and University Kebangsaan Malaysia, and by Science Foundation Ireland, as part of the CLARITY CSET (07/CE/I1147). We would also like to thank School of Communications, Dublin City University, for their supports of this work. 


\section{References}

Bernhaupt, B., Obrist, M., Tscheligi, M. (2007). Usability and usage of iTV services: lessons learned in an Austrian field trial. Computers in Entertainment, 5(2), 6.

Brereton, P. (2008a). How to write textual analysis of a film. CM135 Analyzing Media Content Lecture Notes. School of Communications, Dublin City University.

Brereton, P. (2008b). Teaching with DVD Add-Ons. A Case Study of Smart Films, Donnie Darko (2002) and Run Lola Run (1998). MLA Book Chapter, Teaching Film.

Browne, P., Czirjek, C., Gaughan, G., Gurrin, C., Jones, G., Lee, H., Marlow, S., Mc-Donald, K., Murphy, N., O'Connor, N.E., O'Hare, N., Smeaton, A.F., Ye, J. (2003). Dublin City University video track experiments for TREC 2003. In: Proceedings of the TRECVid Workshop, Gaithersburg, Maryland USA.

Csikszentmihalyi, M. (1991). Flow: The Psychology of Optimal Experience. Harper Perennial New York.

Csikszentmihalyi, M. (1997). Finding flow: The Psychology of Engagement with Everyday Life. Basic Books.

Ewerth, R., Mühling, M., Stadelmann, T., Gllavata, J., Grauer, M., Freisleben, B. (2005). Videana: a software toolkit for scientific film studies. In: Ross, M., Grauer, M., Freisleben, B. (Eds.) Digital Tools in Media Studies, 101-116.

Gurrin, C., MacNeela, P., Smeaton, A.F., Lee, H., Browne, P., McDonald, K. (2004). Físchlár-Nursing, using digital video libraries to teach nursing students. In: WBE 2004 - IASTED International Conference on WebBased Education, 111-116.

Lanagan, J., Smeaton, A.F. (2007). SportsAnno: what do you think? In: RIAO 2007 - Large-Scale Semantic Access to Content (Text, Image, Video and Sound), 39-55.

Lee, H., Smeaton, A.F., O'Connor, N.E., Smyth, B. (2006). User evaluation of Físchlár-News: an automatic broadcast news delivery system. ACM Transactions on Information Systems (TOIS), 24(2), 145-89.

Lee, H., Smeaton, A.F., O’Toole, C., Murphy, N., Marlow, S., O'Connor, N.E. (2000). The Físchlár digital video recording, analysis, and browsing system. In: RIAO 2000 - Content-based Multimedia Information Access, $1390-1399$.

Lehane, B., O'Connor, N. E., Lee, H., Smeaton A.F. (2007). Indexing of fictional video content for event detection and summarisation. EURASIP Journal on Image and Video Processing, Article ID 014615.

Mas, J., Fernandez, G. (2003). Video shot boundary detection based on color histogram. In: Proceedings of the TRECVid Workshop, Gaithersburg, Maryland USA.

McKeown, K.R., Barzilay, R., Evans, D., Hatzivassiloglou, V., Klavans, J.L., Nenkova, A., Sable, C., Schiffman, B., Sigelman, S. (2002). Tracking and summarizing news on a daily basis with Columbia's newsblaster. In: Proceedings of the Second International Conference on Human Language Technology Research, 280-285.

McKeown, K.R., Barzilay, R., Evans, D., Hatzivassiloglou, V., Schiffman, B., Teufel, S. (2001). Columbia multi-document summarization: approach and evaluation. In: Proceedings of the Workshop on Text Summarization, ACM SIGIR Conference.

Mohamad Ali, N., Smeaton, A.F. (2009). Are visual informatics actually useful in practice: a study in a film studies context. Lecture Notes in Computer Science, In: Visual Informatics: Bridging Research and Practice, Vol. 5857/2009, 811-821.

Ronfard, R. (2004). Reading movies: an integrated DVD player for browsing movies and their scripts. In: Proceedings of the 12th Annual ACM International Conference on Multimedia, 740-741.

Smeaton, A.F. (2004). Indexing, browsing, and searching of digital video. Annual Review of Information Science and Technology, 38, 371-410.

Smeaton, A.F., Gilvarry, J., Gormley, G., Tobin, B., Marlow, S., Murphy, N. (1999). An evaluation of alternative techniques for automatic detection of shot boundaries in digital video. In: IMVIP'99 - 3rd Irish Machine Vision and Image Processing Conference, Dublin City University, 8-9.

Smeaton, A.F., Gurrin, C., Lee, H., McDonald, K., Murphy N., O'Connor, N.E., O'Sullivan, D., Smyth, B., Wilson, D. (2004a). The Físchlár-news-stories system: personalised access to an archive of TV news. In: RIAO 2004 - Coupling Approaches, Coupling Media and Coupling Languages for Information Retrieval, $3-17$.

Smeaton, A.F., Lee, H., McDonald, K.(2004b). Experiences of creating four video library collections with the Físchlár system. International Journal on Digital Libraries, 4(1), 42-44. 
N.M. Ali is a senior lecturer/research fellow at the Institute of Visual Informatics, University Kebangsaan Malaysia. She completed her PhD studies in Dublin City University in 2009. Her main research area is human computer interactions particularly in the aspect of user interactions, user interface design and evaluation.

A.F. Smeaton is a full professor in the School of Computing and deputy director of CLARITY, Dublin City University. He has published over 400 book chapters, journal and refereed conference articles. He holds the BSc, MSc and $\mathrm{PhD}$ degrees in computer science from the National University of Ireland. His early research interests covered the application of natural language processing techniques to information retrieval (text) but this then broadened to cover the indexing and content-based retrieval of information in all media, text, and image, audio and especially digital video and now the focus of his work is in information access for human digital memory applications.

\title{
Taikomuju vaizdo priemoniu tyrinèjimas: filmu kūrimo patirtis
}

\author{
Nazlena Mohamad ALI, Alan F. SMEATON
}

Straipsnyje aptariama keletas taikomuju vaizdo priemoniu, kurias studentai paskaitu metu naudojo Dublino universitete. Studentų duomenys buvo fiksuojami ir analizuojami. Tyrime dalyvavo 268 studentai, kurie turejo atlikti tam tikras užduotis. Skatintinas kino filmu konteksto analizavimas, kuris apima gilia turinio bei specialiuju efektu apžvalgą. Techninis daugialypès įrangos tyrinejjimas bei gera vartotojo orientacija daro didelę įtaka mokymuisi. 